Abbreviated Key Title: Sch J Med Case Rep

ISSN 2347-9507 (Print) | ISSN 2347-6559 (Online)

Journal homepage: https://saspublishers.com/sjmcr/

\title{
Amygdalo Glosse Furrow Lipoma Rarely Cause of Dysphagia
}

\author{
N. Belhaj ${ }^{1,3 *}$, C. Nekro ${ }^{1}$, I. Boumendil ${ }^{1}$, H. Rahim ${ }^{1}$, R. Bencheikh ${ }^{2}$, M. A. Benbouzid ${ }^{2}$, L. Essakalli ${ }^{3}$
}

${ }^{1}$ Resident Physician in Otorhinolaryngology, Department of Otorhinolaryngology, Head and Neck Surgery, Ibn Sina University Hospital, Rabat, Morocco

${ }^{2}$ Professor of Otorhinolaryngology, Department of Otorhinolaryngology, Head and Neck Surgery, Ibn Sina University Hospital, Rabat, Morocco

${ }^{3}$ Faculty of Medicine and Pharmacy of Rabat, Mohammed V University, Rabat, Morocco

DOI: $10.36347 /$ simcr.2020.v08i04.002

| Received: 23.03.2020 | Accepted: 31.03.2020 | Published: 05.04.2020

*Corresponding author: Belhaj Najoua

\section{Abstract}

Case Report

Lipoma is a benign tumor developed at the expense of fat cells. The tonsilloglossal fold lipoma is a rare entity we describe in this work the observation of a patient who consulted for dysphagia. We also report in this work a review of the literature.

Keywords: Lipoma, dysphagia, tonsilloglossal.

Copyright @ 2020: This is an open-access article distributed under the terms of the Creative Commons Attribution license which permits unrestricted use, distribution, and reproduction in any medium for non-commercial use (NonCommercial, or CC-BY-NC) provided the original author and source are credited.

\section{INTRODUCTION}

Lipoma is a benign tumor formed of fat cells. It represents $5 \%$ of all benign tumors, but the severity depends on its location such as in tonsilloglossal groove. The tonsilloglossal furrow lipoma is rare and serious due to the symptoms that it can cause despite its benignity.

\section{Case Report}

A 58-years-old patient without a past medical history complaining of dysphagia for 4 months without dysphonia or dyspnea. The clinical examination finds a yellowish, firm, smooth mass appended from the tonsilloglossal groove reaching the base of the tongue.

Cervical CT scan showed the mass without signs of invasion or dissemination to cervical lymph nodes. It is a hypo dense mass with regular contours Figure-1.

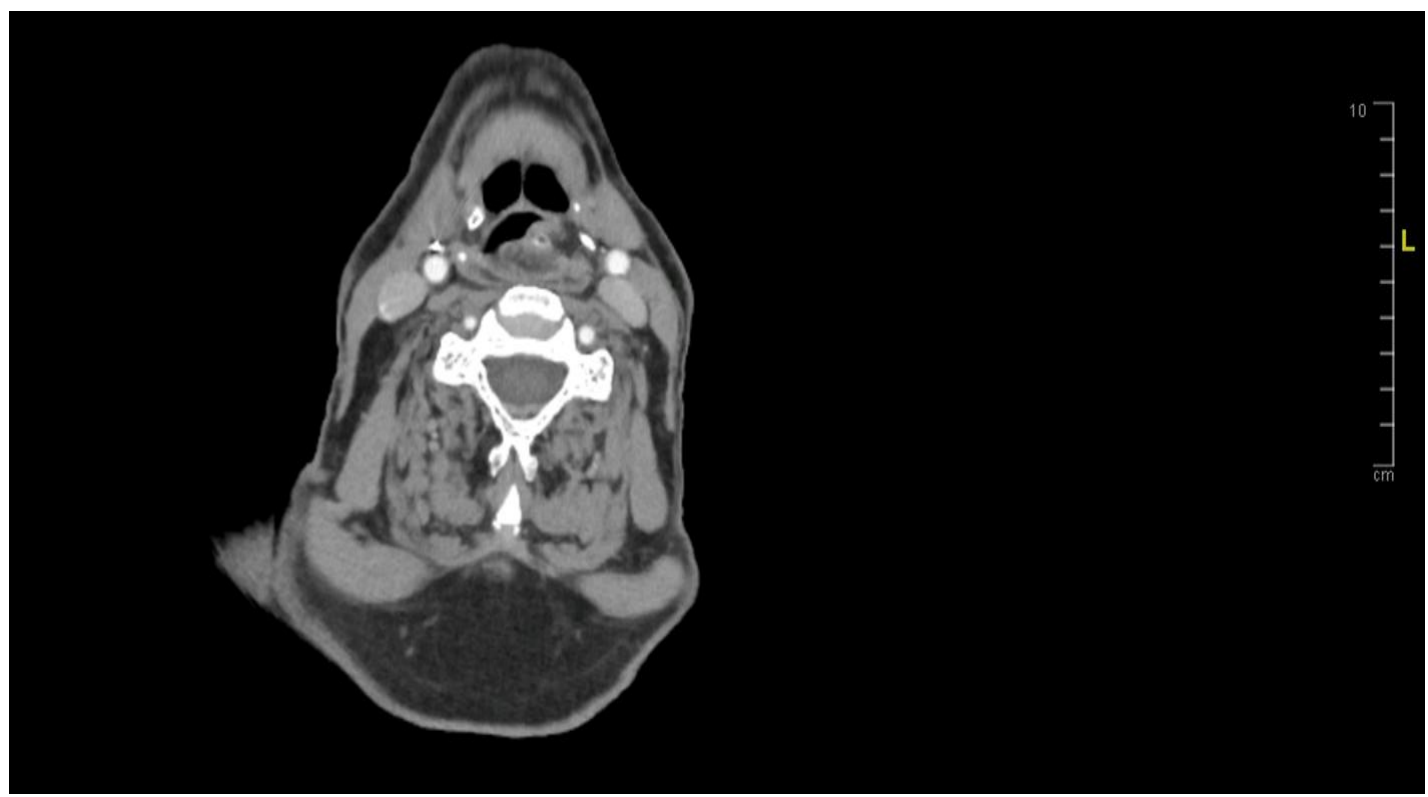




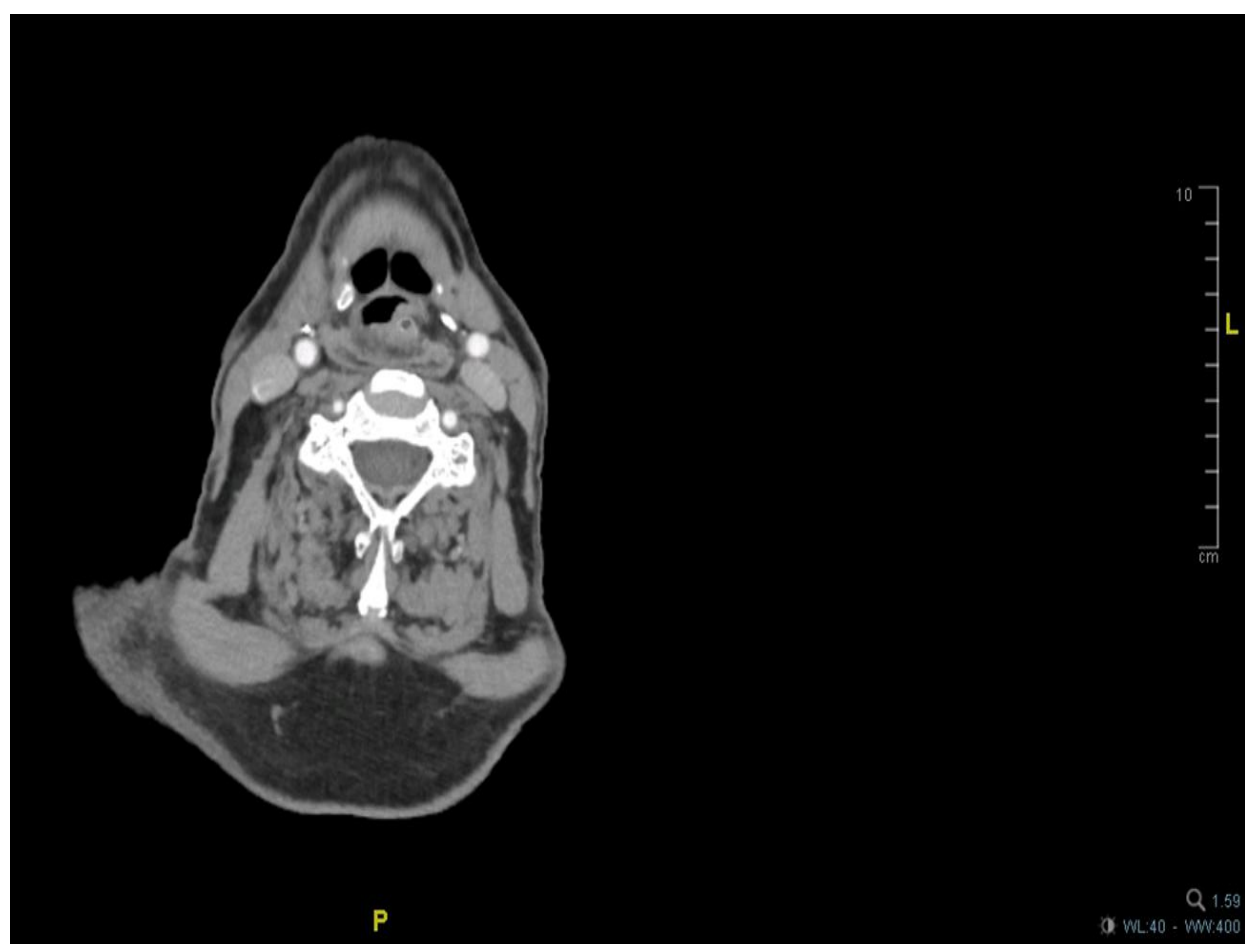

Fig-1: Axial sections of the scanner showing a hypodense image of regular contours depending on the amygdalo glosse groove

However, the clinical and radiological correlation is suggestive of a lipoma. The patient underwent a mass excisional biopsy during a pan endoscopy. The histology of the operating room confirmed our diagnosis by showing a tumor made up of mature adipocytes.

\section{DISCUSSION}

Lipoma of the oral cavity was first described in 1848 by M.Roux as a yellow mass representing a hyperplastic pseudotumor of the gum [1]. It is the most common among the primary mesenchymal tumors of the soft tissue of the head and neck region. Indeed, lipomas represent 15 to $20 \%$ of mesenchymal tumors of the head and neck, and 1 to $5 \%$ of mesenchymal tumors of the oral cavity (1). The fact remains that lipomas in the oral cavity are rare, since they represent only 0.1 to $5 \%$ of the total benign tumors or pseudo-tumors of the oral sphere. They most commonly located in the oral cavity, but they can also be in the buccal floor, large salivary glands, vestibule, palate, retromolar space and lips [1].

The diagnosis of intraoral lipoma is often relatively simple when the location is superficial, in the subcutaneous tissue. When pulled, the yellow color of the adipose tissue appears often transparent through the mucosa, which allows to clinically make an initial diagnosis of suspicion. Through thereafter, the fact that the tumor floats in the fixation fluid is an intraoperative index in favor of the fatty content of the tissue tumor, as well as the Herdt test for fatty liver [4]. Due to its lower density, the adipose tumor tissue floats in the buffered solution of $4 \%$ formaldehyde contained in the vial intended for pathology. For lipomas located deeper, such that intramuscular or perineural lipomas, the diagnosis precise preoperative surgery plays an important role, as clinical examination alone provides too little information to plan for adequate surgical intervention. In this regard, the fine needle puncture (FNP) is considered a tool important from the point of view of diagnosis and planning of the intervention. Using PAF, tissue masses located deep but still palpable, can be punctured during a minimally invasive intervention preoperative in order to obtain a cyto- or histopathological examination, which can be very useful in determining the radicality or the scope of the intervention to be carried out [2].

Histologically, lipomas in the oral sphere are formed of lipocytes. They are surrounded by a fibrous capsule that isolate them from the surrounding tissue. Adipocytes nuclei are generally monomorphic and small. The histological characteristics of lipomas sometimes change by the presence of other mesenchymal components. Based on these different histological characteristics and their mode of growth, lipomas are subdivided into nine subtypes: simple lipomas, fibrolipomas, angiolipomas, infiltrating lipomas (intramuscular), pleomorphic lipomas, osteolipomas, sialolipomas, chondrolipomas, myxolipomas and spindle cell lipomas [3].

Two studies suggest that the tongue could be a target site of the infiltrating (intramuscular) lipoma due to the close proximity relationship between adipose tissue and muscle layer [2]. In addition, it is possible that this lipoma subtype has a higher recurrence rate [2]. 
But to this day this idea remains rather speculative, because there is no of consensus in the literature as to the very existence of this subtype intraorally, and what's more, it's not clear if the previously described intramuscular lipomas are simple lipomas encompassing muscle fibers,reason for their occurrence in the immediate vicinity of muscle tissue [2]. In this case, it is a fibrolipoma surrounded on all sides by a thin connective capsule. This lipoma subtype is one of the most common in the oral sphere [2].

\section{CONCLUSION}

Oral sphere lipomas are benign tumors generally slow growth. Their growth is most often asymptomatic. It is important that the complete excision tumor - or biopsy - is followed by a histopathological examination to confirm the diagnosis of suspected based on the clinic. The recidivism rate is very low. The lipoma of the amygdalo glosse furrow is a rare entity. The severity of this benign pathology rests on the obstruction of the aerodigestive tracts which it involves. Imaging allows a better diagnostic and therapeutic approach. The treatment consists of excision of the tumor by the transoral way.

\section{REFERENCES}

1. Malave DA, Ziccardi VB, Greco R, Patterson GT. Lipoma of the parotid gland: report of a case. Journal of oral and maxillofacial surgery. 1994 Apr 1;52(4):408-11.

2. Bassetti, R., Tomasetti, P., Crameri, M., \& Kuttenberger, J. Benigner odontogener Tumor im Unterkiefer.

3. Bassetti R, Tomasetti P, Kuttenberger J. Clinique de chirurgie buccale et maxillofaciale/chirurgie orale, Hôpital cantonal de Lucerne.

4. Harnisch H, Altermatt HJ, Bornstein MM, française de Jacques Rossier $\mathrm{T}$, Vauthier $\mathrm{T}$. Lipome intra-oral de la region du nerf mentonnier. Schweizer Monatsschrift Fur Zahnmedizin. 2007;117(4):382.

5. Herdt T, Liesman JS, Gerloff BJ, Emery RS. Reduction of serum triacylglycerol-rich lipoprotein concentrations in cows with hepatic lipidosis. American Journal of Veterinary Research. 1983 Feb;44(2):293-6. 